\title{
Femoral Morphology in the Dysplastic Hip: Three-dimensional Characterizations With CT
}

\author{
Joel Wells MD, MPH, Jeffrey J. Nepple MD, Karla Crook BS, \\ James R. Ross MD, Asheesh Bedi MD, Perry Schoenecker MD, \\ John C. Clohisy MD
}

Published online: 17 October 2016

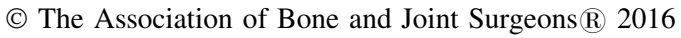

\begin{abstract}
Background Hip dysplasia represents a spectrum of complex deformities on both sides of the joint. Although many studies have described the acetabular side of the deformity, to our knowledge, little is known about the three-dimensional (3-D) head and neck offset differences
\end{abstract}

Each author certifies that he or she, or a member of his or her immediate family, has no funding or commercial associations (eg, consultancies, stock ownership, equity interest, patent/licensing arrangements, etc) that might pose a conflict of interest in connection with the submitted article.

All ICMJE Conflict of Interest Forms for authors and Clinical Orthopaedics and Related Research ${ }^{\circledR}$ editors and board members are on file with the publication and can be viewed on request.

Clinical Orthopaedics and Related Research ${ }^{\circledR}$ neither advocates nor endorses the use of any treatment, drug, or device. Readers are encouraged to always seek additional information, including FDAapproval status, of any drug or device prior to clinical use.

Each author certifies that his or her institution approved the human protocol for this investigation, that all investigations were conducted in conformity with ethical principles of research, and that informed consent for participation in the study was obtained.

This work was performed at Washington University in St Louis, St Louis, MO, USA.

J. Wells, J. J. Nepple, K. Crook, P. Schoenecker, J. C. Clohisy Department of Orthopedic Surgery, Washington University in St Louis, St Louis, MO, USA

J. R. Ross

Broward Orthopedic Specialists, Ft Lauderdale, FL, USA

A. Bedi

Sports Medicine and Shoulder Service, University of Michigan,

Ann Arbor, MI, USA

J. Wells $(\bowtie)$

UT Southwestern Orthopaedic Surgery, 1801 Inwood Road,

Dallas, TX 75390, USA

e-mail: jobuwells@gmail.com of the femora of dysplastic hips. A thorough knowledge of proximal femoral anatomy is important to prevent potential impingement and improve results after acetabular reorientation.

Questions/purposes (1) Are there common proximal femoral characteristics in patients with symptomatic hip dysplasia undergoing periacetabular osteotomy (PAO)? (2) Where is the location of maximal femoral head and neck offset deformity in hip dysplasia? (3) Do certain subgroups of dysplastic hips more commonly have cam-type femoral morphology? (4) Is there a relationship between hip ROM as well as impingement testing and 3-D head and neck offset deformity?

Methods Using our hip preservation database, 153 hips (148 patients) underwent PAO from October 2013 to July 2015. We identified 103 hips in 100 patients with acetabular dysplasia (lateral center-edge angle $\left[\right.$ LCEA] $<20^{\circ}$ ) and who had a Tönnis grade of 0 or 1. Eighty-six patients (86\%) underwent preoperative low-dose pelvic CT scans at our institution as part of the preoperative planning for PAO. It is currently our standard to obtain preoperative low-dose pelvic CT scans $(0.75-1.25 \mathrm{mSv}$, equivalent to three to five AP pelvis radiographs) on all patients before they undergo PAO unless a prior CT scan is performed at an outside institution. Hips with a history of a neuromuscular disorder, prior trauma, prior surgery, radiographic evidence of joint degeneration, ischemic necrosis, or Perthes-like deformities were excluded. Fifty hips in 50 patients met inclusion criteria and had CT scans available for review. Hips were analyzed with Dyonics Plan software and characterized with regard to version, neck-shaft angle, femoral head diameter, head and neck offset, femoral neck length, femoral offset, head center height, trochanteric height, and alpha angle. The maximum head and neck offset deformity was assessed using an entire clockface and 
an alpha angle $\geq 55^{\circ}$ defined coexisting cam morphology. Subgroups included severity of lateral dysplasia: mild (LCEA $15^{\circ}-20^{\circ}$ ) and moderate/severe $\left(\right.$ LCEA $<15^{\circ}$ ). Femoral version subgroups were defined as normal $\left(5^{\circ}-\right.$ $\left.20^{\circ}\right)$, decreased $\left(\leq 5^{\circ}\right)$, or increased $\left(>20^{\circ}\right)$. The senior author (JCC) performed all physical examination testing. Results The mean LCEA was $14^{\circ}\left( \pm 4^{\circ}\right)$, whereas the mean femoral anteversion was $19^{\circ}\left( \pm 12^{\circ}\right)$. Eight hips $(16 \%)$ demonstrated relative femoral retroversion $\left(\leq 5^{\circ}\right)$, whereas $26(52 \%)$ showed excessive femoral anteversion $\left(>20^{\circ}\right)$. Four hips $(8 \%)$ had $\geq 35^{\circ}$ of femoral anteversion. The mean neck-shaft angle was $136^{\circ}\left( \pm 5^{\circ}\right)$. The mean maximum alpha location was 2:00 o'clock ( \pm 45 minutes) and the mean maximum alpha angle was $52^{\circ}\left( \pm 6^{\circ}\right)$. Minimum head-neck offset ratio was located at 1:30 with a mean of $0.14( \pm 0.03)$. An anterior head-neck offset ratio of $\leq 0.17$ or an alpha angle $\geq 55^{\circ}$ was found in $43(86 \%)$ of hips. Twenty-one dysplastic hips (42\%) had an alpha angle $\geq 55^{\circ}$. Mildly dysplastic hips had decreased femoral head and neck offset $(9 \pm 1)$ and head and neck offset ratio $(0.20 \pm 0.03)$ at 12 o'clock compared with moderate/severe dysplastic hips ( $10 \pm 1$ and $0.22 \pm 0.03$, respectively; $\mathrm{p}=0.04$ and $\mathrm{p}=0.01$ ). With the numbers available, we found that hips with excessive femoral anteversion $\left(>20^{\circ}\right)$ had no difference in the alpha angle at 3 o'clock $(42 \pm 7)$ compared with hips with relative femoral retroversion $\left(\leq 5^{\circ} ; 48 \pm 4 ; \mathrm{p}=0.06\right)$. No other differences in femoral morphology were found between hips with mild or moderate/severe dysplasia or in the femoral version subgroups with the numbers available. Anterior impingement test was positive in $76 \%$ of hips with an alpha angle $\geq 55^{\circ}$ and $83 \%$ of the hips with an alpha angle $\leq 55^{\circ}$. No correlation was found between proximal femoral morphology and preoperative ROM.

Conclusions In this subset of dysplastic hips, cam deformity of the femoral head and neck was present in $42 \%$ of hips with maximal head-neck deformity at 2 o'clock, and $82 \%$ had reduced head-neck offset at the 1:30 point. We conclude that cam-type deformities and decreased head-neck offset in developmental dysplasia of the hip are common. Patients should be closely assessed for need of a head and neck osteochondroplasty, especially after acetabular correction. Future prospective studies should evaluate the influence of proximal femoral anatomy on surgical results of PAO for dysplastic hips.

Level of Evidence Level IV, prognostic study.

\section{Introduction}

Hip dysplasia reflects a combination of proximal femoral and acetabular morphologic abnormalities [6-8, 26, 41].
The overlap between hip dysplasia and femoroacetabular impingement (FAI) resulting from underlying femoral deformities is increasingly recognized but remains poorly defined. Relatively little is known about the head-neck geometry and version of the femora of dysplastic hips because the majority of work has focused on defining acetabular anatomy $[15,22-24,41]$ and defining proximal femoral anatomy with regard to its implications for THA $[2,30,35,38]$.

Dysplastic femora have been shown to have shorter necks, smaller and straighter canals, with increased anteversion and aspheric femoral heads with characteristics and variables dependent on the severity of dysplasia $[2,10,12,30,35,38]$. A few studies have assessed femoral anatomy with regard to head and neck offset in mild to moderate dysplasia using radiographic imaging $[1,10,17,33]$. In the course of treating patients with hip dysplasia, we have noted the frequent coexistence of femoral deformity and its association with the need for a concurrent head and neck osteochondroplasty at the time of acetabular correction. We currently assess for secondary impingement intraoperatively after the PAO. The hip must have at least $90^{\circ}$ of flexion and at least $15^{\circ}$ of internal rotation in flexion. If these motion parameters are not met, then inspection of the femoral head-neck junction is performed through an anterior arthrotomy to identify secondary FAI. If present, we perform an osteochondroplasty of the head-neck junction to relieve the potential secondary FAI. Uncommonly, refinement of the PAO reduction is performed to allow functional, impingement-free hip motion. To our knowledge, this association has not been clearly defined with the use of three-dimensional (3-D) CT. The limitations of plain radiographs in the assessment of femoral morphology, particularly for FAI, are well established. Plain radiographic assessment of the proximal femur may have limited reliability and miss deformities depending on the location. With the assessment of the proximal femur in $\mathrm{CT}$, a complete evaluation of every location is performed. The goal of the current study was to define the 3-D femoral anatomy in dysplastic hips using low-dose CT scans and patient-specific 3-D models.

We therefore asked: (1) Are there common proximal femoral characteristics in patients with symptomatic hip dysplasia undergoing PAO? (2) Where is the location of maximal femoral head and neck offset deformity in hip dysplasia? (3) Do certain subgroups of dysplastic hips, defined by severity of lateral dysplasia and femoral version, more commonly have cam-type femoral morphology? (4) Is there a relationship between clinical ROM as well as impingement testing and 3-D head and neck offset deformity? 


\section{Materials and Methods}

Using our hip preservation database, we identified 153 hips (148 patients) that underwent PAO from October 2013 to July 2015. Of these, 103 hips in 100 patients had symptomatic (pain and functional limitations) [32] acetabular dysplasia (lateral center-edge angle $\left[\right.$ LCEA] $<20^{\circ}$ ) and a Tönnis grade of 0 or 1 on plain AP radiographs $[39,40,44]$. Eighty-six of these patients $(86 \%)$ underwent preoperative low-dose pelvic CT scans at our institution as part of the preoperative planning for PAO. Furthermore, hips with a history of a neuromuscular disorder, prior trauma, prior surgery, radiographic evidence of joint degeneration, ischemic necrosis, Perthes-like deformities (large aspherical femoral head, a short femoral neck, and a high-riding greater trochanter) $[9,11]$ and inadequate imaging were excluded. In the cases of bilateral procedures, only the first surgical side was included. Fifty hips in 50 patients met inclusion criteria. It is currently our standard to obtain preoperative low-dose pelvic CT scans $(0.75-1.25 \mathrm{mSv}$, equivalent to three to five AP pelvis

Table 1. Patient demographics

\begin{tabular}{ll}
\hline Characteristic & $\begin{array}{l}\text { Acetabular } \\
\text { dysplasia }(\mathrm{n}=50)\end{array}$ \\
\hline Age (years), mean (range) & $26(13-49)$ \\
Gender, female $(\%)$ & $45(90 \%)$ \\
Height (inches), mean (range) & $66(60-74)$ \\
Weight (pounds), mean (range) & $152(103-250)$ \\
BMI $\left(\mathrm{kg} / \mathrm{m}^{2}\right)$, mean (range) & $24(19-34)$ \\
\hline
\end{tabular}

$\mathrm{BMI}=$ body mass index. radiographs) on all patients before they undergo PAO unless a prior CT scan has been performed at an outside institution. The mean age was 26 years (range, 1349 years) and there were 45 females (90\%) and five males (10\%) (Table 1).

Institutional internal review board approval was obtained for this study.

The preoperative CT scans were analyzed in a CT-based computer modeling software program (Dyonics Plan Hip Impingement Planning System; Smith \& Nephew Endoscopy, Andover, MA, USA) to generate patient-specific, 3$\mathrm{D}$ models of the hip. For each patient, DICOM images were converted to 3-D models using the Dyonics Plan platform. With this program, axial and coronal views of the femoral head are generated and a computer-automated best-fit sphere is created. Accounting for all clockface possibilities, the program then uses an automated algorithm based on radial sequences to determine the maximum alpha angle and its location (Fig. 1). An orthopaedic surgeon (JW) reviewed all software images to confirm and accepted the computer-determined location for the automated alpha angle and made all other radiographic measurements. The LCEA and Tönnis angles were measured off of the AP radiograph; otherwise, all measurements were 3-D-based CT measurements. Measurements were taken at two different settings 2 weeks apart to determine intrarater reliability.

The following variables were calculated: (1) the center and diameter of the femoral head were obtained with a best-fit circle and calculated femoral head diameter; (2) the length of the femoral neck was defined as the distance between two points on the neck axis, one located at the center of the femoral head and the other at the medullary

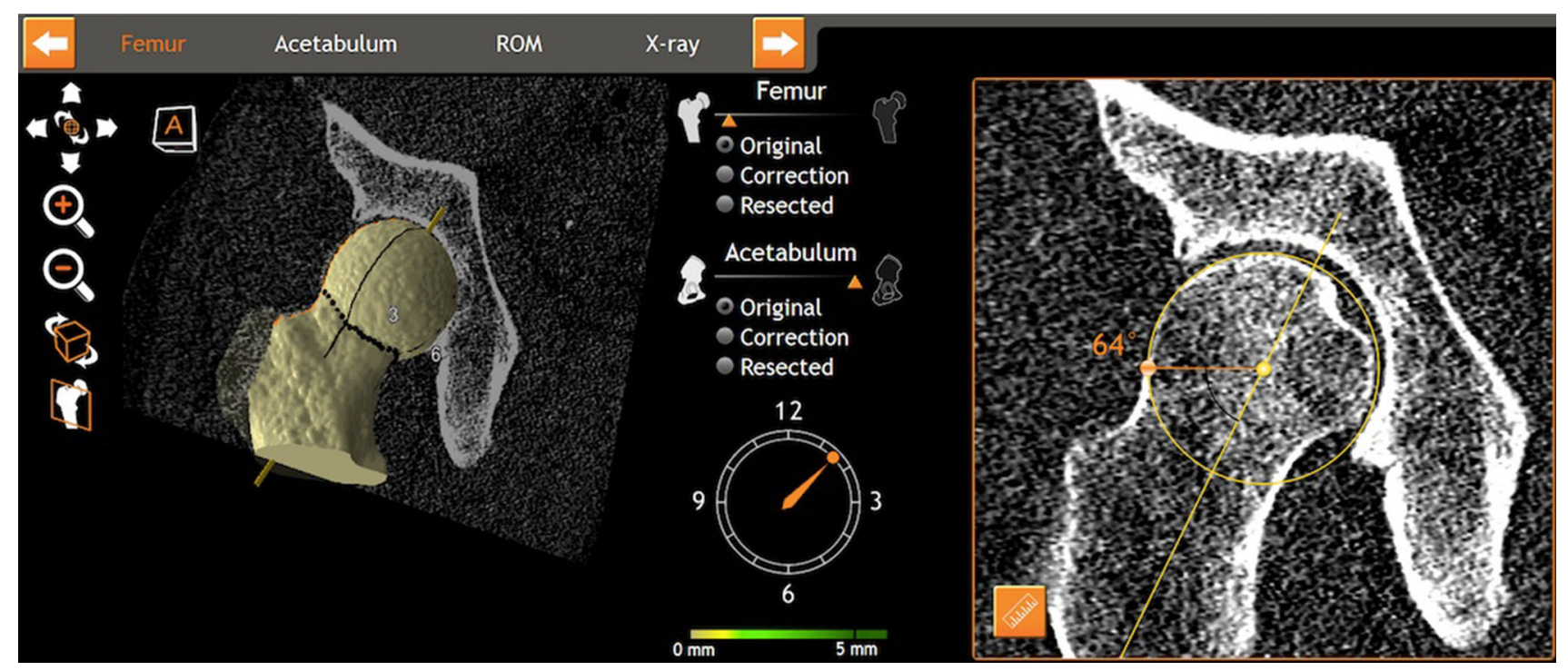

Fig. 1 This is an example of the alpha angle measurement using CT and 3-D reconstructions. 


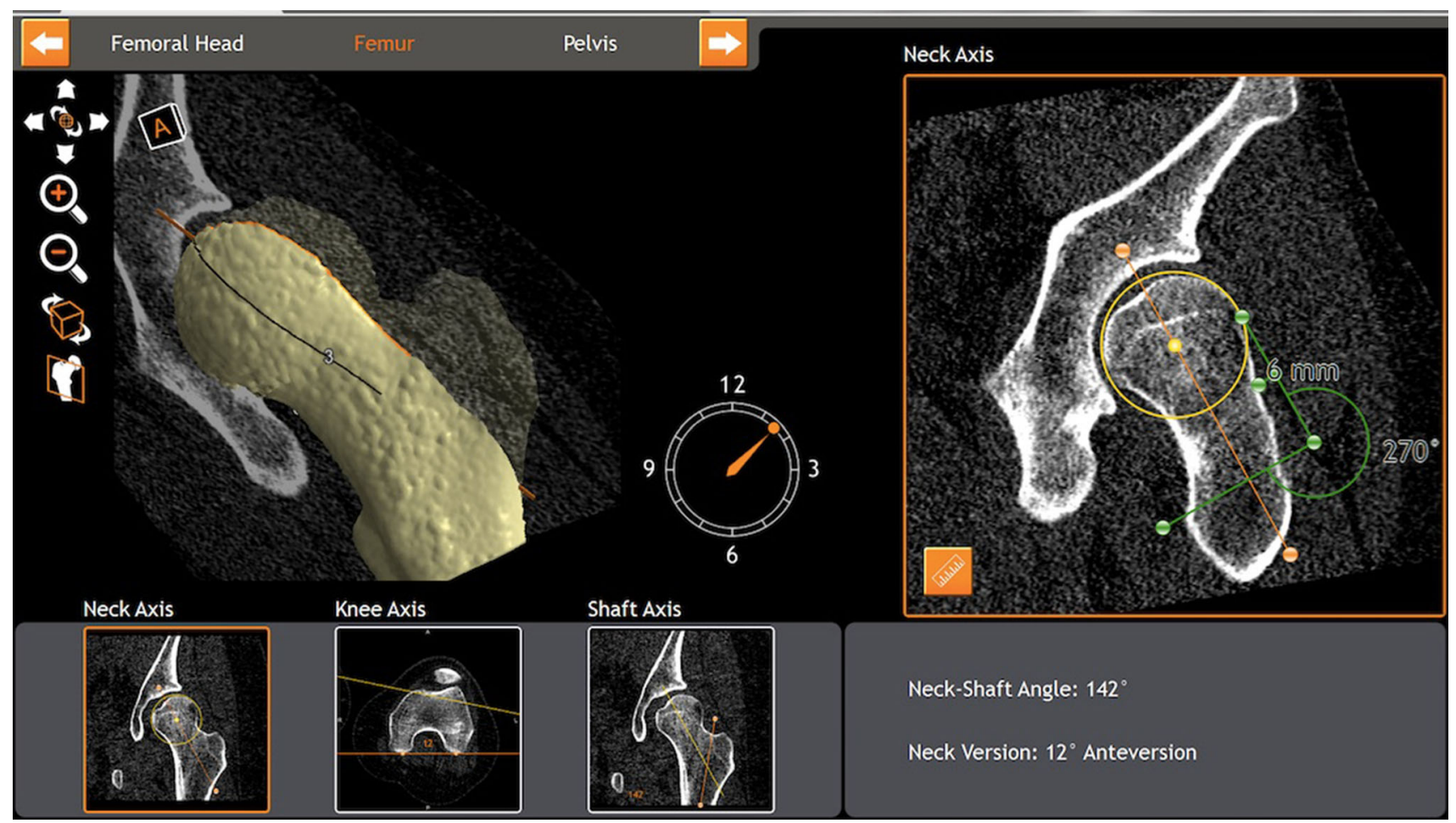

Fig. 2 This is an example of the superior head and neck offset measurement using CT and 3-D reconstructions.

axis of the femur that is centered down the femoral neck $[30,35,38]$; (3) the height of the head center was measured as the distance from the center of the lesser trochanter to the center of the femoral head parallel to the medullary axis $[30,35,38]$; (4) the height of the greater trochanter was defined as the center of the femoral head relative to the tip of the greater trochanter [30, 35, 38]; (5) femoral offset was defined as the distance of a perpendicular line between the center of the femoral head and the femoral medullary axis $[30,35,38]$; (6) the neck-shaft angle (NSA) was defined as the angle between the medullary axis and the neck axis $[4,30,35,38]$; (7) version was defined as the angle between the femoral neck axis and tangent to the posterior femoral condyles in a plane perpendicular to the medullary axis $[5,30,38,40]$; (8) location of the head-neck measurement was represented with a standard clockface position where the 3:00 position is anterior. The alpha angle was measured as the angle between the femoral head neck axis and the point at which the femoral head deviates from a best-fit circle of the femoral head [31] (Fig. 1). The maximum alpha angle reported the maximum alpha angle of the entire clockface; (9) femoral head-neck offset was measured as the distance between a parallel line drawn through the anterior most aspect of the femoral neck that is parallel with a line through the axis of the neck and a parallel line drawn along the anterior aspect of the femoral head. Femoral head-neck offset was measured at 12, 1:30, and 3 o'clock (Fig. 2) [6, 13, 27, 34, 43]; and (10) headneck offset ratio (HNOR) was measured by taking the femoral head-neck offset measurement and dividing by the femoral head diameter $[6,10,34]$.

Hips with an alpha angle $\geq 55^{\circ}$ were classified as having coexisting cam morphology [16, 31,37]. We further assessed subgroups to try to identify relationships between proximal femoral characteristics and head-neck offset abnormalities. Subgroups were divided based on severity of lateral dysplasia and femoral version. Severity of lateral dysplasia was defined as mild when the LCEA was $15^{\circ}$ $20^{\circ}$ and moderate/severe when the LCEA was $<15^{\circ}$. With regard to femoral version, we defined normal as $5^{\circ}-20^{\circ}$, decreased $\leq 5^{\circ}$, and increased $>20^{\circ}$ as reported previously [14, 18]. In addition, each patient underwent preoperative physical examination, including passive ROM testing and anterior impingement testing [19]. The senior surgeon (JCC) examined all patients before PAO and assessed the hip ROM for flexion, internal rotation in flexion, external rotation in flexion, abduction, adduction, internal rotation in extension, and external rotation in extension.

\section{Statistical Analysis}

Demographic data are reported as mean (range). Univariate statistical analysis was used to compare continuous and 
categorical variables between dysplasia subtypes. Chisquare test was used to compare categorical variables (or Fisher's exact test). Student's t-test (two groups) or oneway analysis of variance (ANOVA) (more than two groups) was used to compare continuous variables between groups. Statistical comparison of continuous variables among more than two groups was analyzed with one-way ANOVA with Tukey post hoc testing of statistically

Table 2. Preoperative characteristics for acetabular dysplasia

\begin{tabular}{ll}
\hline Variables & $\begin{array}{l}\text { Dysplastic } \\
\text { hips }(\mathrm{n}=50)\end{array}$ \\
\hline Wiberg LCEA (degrees; mean $\pm \mathrm{SD})$ & $14 \pm 4$ \\
Tönnis angle (degrees; mean $\pm \mathrm{SD})$ & $16 \pm 5$ \\
Tönnis grade & \\
0 & $33(66 \%)$ \\
1 & $17(34 \%)$ \\
\hline
\end{tabular}

LCEA = lateral center-edge angle.

Table 3. Anatomic characteristics of acetabular dysplasia

\begin{tabular}{|c|c|}
\hline Variables & $\begin{array}{l}\text { Dysplastic } \\
\text { hips }(\mathrm{n}=50)\end{array}$ \\
\hline Femoral neck length ( $\mathrm{mm}$; mean $\pm \mathrm{SD}$ ) & $50 \pm 5$ \\
\hline Head center height $(\mathrm{mm}$; mean $\pm \mathrm{SD})$ & $59 \pm 6$ \\
\hline Greater trochanteric height $(\mathrm{mm}$; mean $\pm \mathrm{SD})$ & $-5 \pm 3$ \\
\hline Femoral head diameter $(\mathrm{mm}$; mean $\pm \mathrm{SD})$ & $46 \pm 3$ \\
\hline Femoral offset $(\mathrm{mm} ;$ mean $\pm \mathrm{SD})$ & $37 \pm 4$ \\
\hline Neck-shaft angle (degrees; mean \pm SD) & $136 \pm 5$ \\
\hline Femoral version (degrees; mean \pm SD) & $19 \pm 12$ \\
\hline \multicolumn{2}{|l|}{ Alpha angle* (degrees; mean \pm SD) } \\
\hline 9:00 & $36 \pm 3$ \\
\hline $10: 30$ & $35 \pm 3$ \\
\hline $12: 00$ & $39 \pm 3$ \\
\hline $1: 30$ & $49 \pm 6$ \\
\hline 3:00 & $44 \pm 8$ \\
\hline $\begin{array}{l}\text { Maximum alpha angle* } \\
\quad(\text { degrees; mean } \pm \text { SD) }\end{array}$ & $53 \pm 6$ \\
\hline $\begin{array}{l}\text { Maximum alpha angle } \\
\text { location* (o'clock; mean } \pm \text { SD) }\end{array}$ & $2: 00 \pm 0: 45$ \\
\hline \multicolumn{2}{|l|}{$\begin{array}{l}\text { Femoral head-neck offset* } \\
\quad(\mathrm{mm} ; \text { mean } \pm \mathrm{SD})\end{array}$} \\
\hline $12: 00$ & $9 \pm 1$ \\
\hline $1: 30$ & $6 \pm 1$ \\
\hline 3:00 & $8 \pm 2$ \\
\hline \multicolumn{2}{|l|}{ Femoral head-neck offset ratio (mean \pm SD) } \\
\hline $12: 00$ & $0.21 \pm 0.03$ \\
\hline $1: 30$ & $0.14 \pm 0.03$ \\
\hline 3:00 & $0.17 \pm 0.03$ \\
\hline
\end{tabular}

*Alpha angle, head-neck offset, and head-neck offset ratio measured according to the clock position. significant results. A $\mathrm{p}$ value $<0.05$ was considered significant.

Statistical analysis of radiographic parameters was performed using intraclass correlation coefficients (ICCs) for continuous measurements. All measurements demonstrated excellent reliability. ICCs were: 1.0 for femoral version, 1.0 for NSA, 0.97 for head and neck offset, 1.0 for femoral neck length, 0.99 for femoral offset, 0.99 for head center height, 0.99 for trochanteric height, and 1.0 for alpha angle measurement.

\section{Results}

The mean LCEA and Tönnis angles ware $14^{\circ}\left( \pm 4^{\circ}\right)$ and $16^{\circ}\left( \pm 5^{\circ}\right)$ (Table 2), respectively, whereas the mean femoral anteversion was $19^{\circ}\left( \pm 12^{\circ}\right)$. Eight hips $(16 \%)$ demonstrated relative femoral retroversion $\left(\leq 5^{\circ}\right)$, whereas $26(52 \%)$ showed excessive femoral anteversion $\left(>20^{\circ}\right)$. Four hips $(8 \%)$ had $\geq 35^{\circ}$ of femoral anteversion. The mean NSA was $136^{\circ}\left( \pm 5^{\circ}\right)$.

Twenty-one $(42 \%)$ dysplastic hips had alpha angles $\geq 55^{\circ}$ and therefore were classified as having cam morphology. The mean maximum alpha location was 2:00 o'clock ( \pm 45 minutes) and the mean maximum alpha angle was $52^{\circ}\left( \pm 6^{\circ}\right)$. Head-neck offset ratio minimum was located at 1:30 with a mean of $0.14( \pm 0.03)$ (Table 3$)$. An anterior head-neck offset ratio of $\leq 0.17$ or an alpha angle $\geq 55^{\circ}$ was found in 43 of $103(86 \%)$ hips. Sixty percent of males (three patients) and $40 \%$ of females (18 patients) had an alpha angle $\geq 55^{\circ}$. If a cutoff of $\geq 60^{\circ}$ was used for cam-type morphology, $60 \%$ of males (three patients) and 7\% (three patients) of females had cam-type morphology with a mean location of maximum deformity at the 2:00 o'clock position. On the other hand, if a cutoff of $\geq 50^{\circ}$ was used for cam-type morphology, $80 \%$ of males (four patients) and 76\% (34 patients) of females had morphology consistent with cam type with a mean location of maximum deformity also at the 2:00 o'clock position. The majority of patients (41 patients [82\%]) had an abnormal head and neck offset (HNOR $<0.17$ ).

Mildly dysplastic hips (LCEA $15^{\circ}-20^{\circ}$ ) had decreased femoral head and neck offset $(9 \pm 1)$ and HNOR $(0.20 \pm 0.03)$ at 12 o'clock compared with moderate/severe dysplastic hips $\left(\right.$ LCEA $\left.<15^{\circ}\right) \quad(10 \pm 1$ and $0.22 \pm 0.03$, respectively; $\mathrm{p}=0.04$ and $\mathrm{p}=0.01)$. We found that hips with excessive femoral anteversion $\left(>20^{\circ}\right)$ had no difference in the alpha angle at 1:30 and 3 o'clock (49 \pm 6 and $42 \pm 7$ ) compared with hips with relative femoral retroversion $\left(\leq 5^{\circ} ; 51 \pm 7\right.$ and $48 \pm 4 ; p=0.92$ and $\mathrm{p}=0.06$, respectively). No other differences in femoral morphology were found between hips with mild or moderate/severe dysplasia (Table 4) or in the femoral 
Table 4. Severity of dysplasia and head-neck offset characteristics

\begin{tabular}{|c|c|c|c|}
\hline Variables & Mild $\left(\right.$ LCEA $\left.15^{\circ}-20^{\circ}\right)(n=28)$ & Moderate/severe $\left(\right.$ LCEA $\left.<15^{\circ}\right)(\mathrm{n}=22)$ & $\mathrm{p}$ value \\
\hline \multicolumn{4}{|l|}{ Alpha angle* (degrees; mean \pm SD) } \\
\hline 9:00 & $36 \pm 4$ & $36 \pm 3$ & 0.97 \\
\hline $10: 30$ & $35 \pm 3$ & $35 \pm 4$ & 0.77 \\
\hline $12: 00$ & $40 \pm 3$ & $39 \pm 3$ & 0.25 \\
\hline $1: 30$ & $49 \pm 6$ & $50 \pm 6$ & 0.79 \\
\hline 3:00 & $43 \pm 6$ & $46 \pm 8$ & 0.14 \\
\hline Maximum alpha angle* (degrees; mean $\pm \mathrm{SD}$ ) & $52 \pm 7$ & $54 \pm 6$ & 0.28 \\
\hline Maximum alpha angle location* (o'clock; mean \pm SD) & $1: 45 \pm 30$ minutes & $2: 15 \pm 60$ minutes & 0.18 \\
\hline \multicolumn{4}{|l|}{ Femoral head-neck offset* (mm; mean \pm SD) } \\
\hline $12: 00$ & $9 \pm 1$ & $10 \pm 1$ & 0.04 \\
\hline $1: 30$ & $6 \pm 1$ & $7 \pm 1$ & 0.37 \\
\hline 3:00 & $8 \pm 2$ & $8 \pm 2$ & 0.64 \\
\hline \multicolumn{4}{|l|}{ Femoral head-neck offset ratio (mean $\pm \mathrm{SD}$ ) } \\
\hline $12: 00$ & $0.20 \pm 0.03$ & $0.22 \pm 0.03$ & 0.01 \\
\hline $1: 30$ & $0.14 \pm 0.03$ & $0.15 \pm 0.03$ & 0.31 \\
\hline 3:00 & $0.17 \pm 0.04$ & $0.17 \pm 0.03$ & 0.75 \\
\hline Minimum head-neck offset ratio (mean \pm SD) & $0.13 \pm 0.03$ & $0.14 \pm 0.03$ & 0.27 \\
\hline
\end{tabular}

*Alpha angle, head-neck offset, and head-neck offset ratio measured according to the clockface position; 3:00 position is anterior; LCEA $=$ lateral center-edge angle.

version subgroups (Table 5). The mean anterior head-neck offset at 1:30 for the mildly dysplastic hips was $6 \mathrm{~mm}$ $( \pm 1 \mathrm{~mm})$ and there was no difference in more severely dysplastic hips $(7 \pm 1 \mathrm{~mm} ; \mathrm{p}=0.37)$. There was no difference in minimum head-neck offset ratio at 1:30 for patients with mild dysplasia versus moderate/severe dysplasia $\quad(0.13 \pm 0.03 \quad$ versus $0.14 \pm 0.03 ; \quad \mathrm{p}=0.31)$. Maximum alpha angle was the same for the two groups $\left(52^{\circ} \pm 7^{\circ}\right.$ versus $54^{\circ} \pm 6^{\circ} ; \mathrm{p}=0.28$; Table 4$)$. Hips with femoral anteversion between $5^{\circ}$ and $20^{\circ}$ had no difference in maximum alpha angle $(53 \pm 6)$ compared with hips with relative femoral retroversion $(55 \pm 7)$ and excessive femoral anteversion (52 $\pm 6 ; \mathrm{p}=0.64$; Table 5).

The anterior impingement test was positive in 16 hips (76\%) with an alpha angle $\geq 55^{\circ}$ and 24 hips (83\%) with an alpha angle $\leq 55^{\circ}$. No difference was found between those hips with and without cam morphology with regard to preoperative flexion $(100 \pm 0.03$ versus $98 \pm 15$; $\mathrm{p}=0.41)$ nor internal rotation in flexion $(20 \pm 8$ versus $19 \pm 10 ; \mathrm{p}=0.65$; Table 6).

\section{Discussion}

The overlap between hip dysplasia and FAI remains poorly defined. The underlying femoral deformities in hip dysplasia are increasingly recognized, but the 3-D geometry of the proximal femur and its variability have been poorly characterized. We analyzed 50 hips with symptomatic acetabular dysplasia and sought to characterize the 3-D proximal femoral morphology in dysplastic hips undergoing PAO. An abnormality of the head and neck was present in $43(86 \%)$ of the dysplastic hips and coexisting head asphericity did indeed exist in $21(42 \%)$ hips with a mean location at the 2:00 o'clock position. This is important to prevent potential secondary FAI after acetabular correction.

Our study was limited in that this is a select retrospective group of patients without a control. Selection bias was mitigated by our inclusion criteria, which was well defined and because of such criteria, these results only apply to patients with symptomatic acetabular dysplasia without prior hip trauma or neuromuscular or connective tissue disease who are undergoing PAO. Therefore, this study may be valuable for preoperative and intraoperative planning in PAO. Although our study included patients with well-defined inclusion criteria and complete sets of data, there is an inherent selection bias because acetabular dysplasia is more common in the female population [42]. Sex differences cannot be well determined in this study because of this. We are unable to answer if male dysplastic patients present with symptoms more like that of impingement with reduced ROM and thereby potentially benefiting from associated femoral osteochondroplasty at the time of PAO. Dysplastic hips are complex with variable anatomy and 
Table 5. Severity of dysplasia and head-neck offset characteristics

\begin{tabular}{|c|c|c|c|c|}
\hline Variables & $\begin{array}{l}\text { Femoral version } \\
\left(5^{\circ}-20^{\circ}\right)(\mathrm{n}=17)\end{array}$ & $\begin{array}{l}\text { Relative femoral } \\
\text { retroversion }\left(\leq 5^{\circ}\right)(\mathrm{n}=7)\end{array}$ & $\begin{array}{l}\text { Excessive femoral } \\
\text { anteversion }\left(>20^{\circ}\right)(\mathrm{n}=26)\end{array}$ & $\mathrm{p}$ value \\
\hline \multicolumn{5}{|l|}{ Alpha angle* (degrees; mean \pm SD) } \\
\hline 9:00 & $37 \pm 3$ & $37 \pm 2$ & $35 \pm 3$ & 0.37 \\
\hline $10: 30$ & $35 \pm 3$ & $36 \pm 4$ & $35 \pm 3$ & 0.89 \\
\hline $12: 00$ & $39 \pm 3$ & $38 \pm 4$ & $39 \pm 3$ & 0.64 \\
\hline $1: 30$ & $49 \pm 6$ & $51 \pm 7$ & $49 \pm 6$ & 0.92 \\
\hline 3:00 & $47 \pm 8$ & $48 \pm 4$ & $42 \pm 7$ & $0.06^{\dagger}$ \\
\hline $\begin{array}{l}\text { Maximum alpha angle* } \\
\quad(\text { degrees; mean } \pm \text { SD) }\end{array}$ & $53 \pm 6$ & $55 \pm 7$ & $52 \pm 6$ & 0.64 \\
\hline $\begin{array}{l}\text { Maximum alpha angle } \\
\text { location* (o'clock; mean } \pm \text { SD) }\end{array}$ & $2: 15 \pm 30$ minutes & $2: 00 \pm 45$ minutes & $2: 00 \pm 45$ minutes & 0.67 \\
\hline \multicolumn{5}{|c|}{ Femoral head-neck offset* (mm; mean SD) } \\
\hline $12: 00$ & $10 \pm 2$ & $10 \pm 1$ & $9 \pm 1$ & 0.42 \\
\hline $1: 30$ & $7 \pm 1$ & $7 \pm 1$ & $6 \pm 1$ & 0.43 \\
\hline 3:00 & $8 \pm 1$ & $8 \pm 2$ & $8 \pm 2$ & 0.94 \\
\hline \multicolumn{5}{|c|}{ Femoral head-neck offset ratio (mean $\pm \mathrm{SD}$ ) } \\
\hline $12: 00$ & $0.21 \pm 0.03$ & $0.21 \pm 0.02$ & $0.20 \pm 0.02$ & 0.49 \\
\hline $1: 30$ & $0.15 \pm 0.03$ & $0.14 \pm 0.02$ & $0.14 \pm 0.03$ & 0.30 \\
\hline 3:00 & $0.17 \pm 0.03$ & $0.17 \pm 0.03$ & $0.17 \pm 0.04$ & 0.98 \\
\hline
\end{tabular}

Probability values based on univariate comparisons between relative femoral retroversion and excessive femoral anteversion hips; * alpha angle, head-neck offset, and head-neck offset ratio measured according to the clock position; ${ }^{\dagger}$ analysis of variance $\mathrm{p}=0.04$; post hoc Tukey testing not significant ( $\mathrm{p}$ values 1 versus $2 \mathrm{p}=1.00,2$ versus $3 \mathrm{p}=0.06,1$ versus $3 \mathrm{p}=0.21$ ).

Table 6. Alpha angle and clinical testing

\begin{tabular}{llll}
\hline Variables & Alpha angle $\left(<55^{\circ}\right)(\mathrm{n}=29)$ & Alpha angle $\left(\geq 55^{\circ}\right)(\mathrm{n}=21)$ & $\mathrm{p}$ value \\
\hline Internal rotation in flexion (degrees; mean $\pm \mathrm{SD})$ & $20 \pm 8$ & $35 \pm 10$ & 0.65 \\
External rotation in flexion (degrees; mean $\pm \mathrm{SD})$ & $39 \pm 14$ & $98 \pm 15$ & 0.30 \\
Flexion (degrees; mean $\pm \mathrm{SD})$ & $100 \pm 5$ & $36 \pm 11$ & $16 \pm 7$ \\
Abduction (degrees; mean $\pm \mathrm{SD})$ & $36 \pm 9$ & $31 \pm 13$ & 0.41 \\
Adduction (degrees; mean $\pm \mathrm{SD})$ & $15 \pm 4$ & $14 \pm 8$ & 76 \\
External rotation in extension (degrees; mean $\pm \mathrm{SD})$ & $34 \pm 12$ & $76 \%$ & 0.74 \\
Internal rotation in extension (degrees; mean $\pm \mathrm{SD})$ & $13 \pm 4$ & $83 \%$ &
\end{tabular}

Chi-square comparing hips with an alpha angle $<55^{\circ}$ with those with an alpha angle $\geq 55$.

subtle differences and we were only able to evaluate 50 dysplastic hips. The primary purpose of the current study was descriptive. Statistical comparisons between subgroups were performed as a secondary outcome. Post hoc power analysis showed adequate power to demonstrate $80 \%$ power at $\mathrm{p}=0.05$ to detect a $6^{\circ}$ difference in alpha angle between subgroups with mild versus moderate dysplasia. Our study is underpowered to detect smaller differences, which are less likely to be clinically relevant. The mean age was 26 years (range, 13-49 years) and to limit variability that may occur with age and subsequent arthrosis, only patients with a Tönnis grade of 0 or 1 were included.
Another limitation is the descriptive design. Although we report a detailed analysis of proximal femoral anatomy, we understand that impingement and instability are complex pathologic conditions that can be misrepresented by numeric values. Large alpha angles and decreased head and neck offset do not always indicate impingement, and conversely impingement, including extraarticular variants, can exist in smaller alpha angles. Nevertheless, we added clinical data including ROM and impingement testing to further strengthen our study and this analysis can serve as a framework for prospective studies evaluating treatment and outcomes in dysplastic hips. 
Radiographic evaluation demonstrates that dysplastic hips can have signs of coexisting radiographic impingement $[1,10,17,33]$. Studies that investigate comprehensive head and neck offset or identify the exact location of maximal deformity using 3-D remodeling are limited [20, 28]. We aimed to characterize the proximal femoral anatomy in patients with classic dysplasia (LCEA $<20^{\circ}$ ), determine the rate and exact location of cam deformity in hip dysplasia, and investigate if changes in the severity of dysplasia and femoral version correlated with head-neck offset deformity. Kohno and colleagues [20] assessed cam deformities in Japanese dysplastic hips and found that cam deformities occurred at relatively high frequency in the pre-/early arthrosis group as well as the advanced arthrosis group. We solely looked at only patients with none to minimal arthrosis (Tönnis grade of 0 or 1 ) in a population from the United States and found a high frequency of cam-type morphology.

Noble et al. [30] and Sugano et al. [38] showed that the severity of dysplasia did have an impact on proximal femoral morphology. They graded severity according to the Crowe classification [12] and found that more severely dislocated hips had greater femoral head deformities, straighter intramedullary canals, and decreased NSAs. In our cohort, none of the 50 hips were dislocated, and we classified severity based on LCEA. There was no difference in NSA, femoral head diameter, femoral neck length, femoral offset, head center height, femoral version, or trochanteric height between the two groups based on LCEA severity. Both groups had mean alpha angles greater than $50^{\circ}\left(52^{\circ} \pm 7^{\circ}\right.$ in mild dysplasia versus $54^{\circ} \pm 6^{\circ}$ in moderate/severe) $(\mathrm{p}=0.28)$. This is an important finding because after correction of dysplasia with PAO, all dysplastic hips could be at increased risk for secondary intraarticular impingement.

Anderson and colleagues [1] assessed a group of 164 symptomatic dysplastic hips before undergoing PAO. They found a prevalence of cam deformities of $10 \%$ and they concluded that cam impingement is overdiagnosed in developmental dysplasia of the hip and this could possibly lead to unnecessary femoral osteochondroplasty procedures. In this study, only AP and frog-lateral radiographs were evaluated. Plain radiographs are inadequate to assess the complex 3-D anatomy of the proximal femur and may miss the location of maximal head-neck deformity, especially if a Dunn or extended neck lateral radiograph is not obtained [3, 7, 21, 29]. Nepple et al. [29] found a substantial correlation between radiographs and corresponding radial locations on $\mathrm{CT}$ with frog-lateral radiographs corresponding more to the 3:00 o'clock position, whereas the Dunn view more closely represented the 2:00 o'clock position. We have found that dysplastic hips on average had the site of maximal alpha angle more at the 2:00 o'clock position and could easily be missed on AP and frog-lateral radiographs.

Milone et al. [25] reported a series of 100 hips treated for symptomatic FAI and analyzed the proximal femoral morphology using CT and 3-D analysis software and they concluded that the mean peak deformity was at the 1:23 o'clock position and $60 \%$ of maximum alpha angles lying between 12:45 and 1:45. Similarly, Ross et al. [36] analyzed proximal femoral morphology using CT-based computer modeling software in hockey position players and goalies and found maximal deformities at 1:00 to 1:45, although goalies had a maximal alpha angle more lateral than that of position players. Nakahara and colleagues [28] evaluated femoral anatomy using surface modeling and collision data analysis to determine impingement in developmental dysplasia of the hip (DDH). They reported larger alpha angles between 2 o'clock and 3 o'clock in patients with DDH compared with nondysplastic control subjects. In our series of 50 dysplastic hips, $86 \%$ had a HNOR of $\leq 0.17$ or an alpha angle $\geq 55^{\circ}$ with a mean maximum alpha location at the 2:00 o'clock position, slightly more anterior than previously reported for FAI and similar to the findings of Nakahara et al. Further subdividing severity of dysplasia and severity of femoral version did not predict alpha angle or location of maximal deformity.

Of interest is the prevalence of relative femoral retroversion in this patient population. Relative femoral retroversion may be a risk factor for a poorer outcome after hip arthroscopy for FAI [14] and isolated cam impingement in nondysplastic hips has been shown to correlate with decreased femoral anteversion [5]. In our cohort, there were eight hips $(16 \%)$ that had relative femoral retroversion and we were unable to find a correlation between relative femoral retroversion and larger alpha angles. It is still unclear as to the importance of version on the outcomes after PAO and the indications for surgical treatment of femoral torsional abnormalities at the time of surgery remain controversial. The current study reports that although uncommon, hips with relative femoral retroversion do exist in the dysplastic hip population.

Nakahara et al. reported no correlation between alpha angle and ROM using collision data analysis [28]. They therefore concluded that anterior intraarticular impingement seldom occurs in DDH during daily activities, even in the presence of a retroverted acetabulum, and that extraarticular impingement more commonly acts as the endpoint to ROM in DDH [28]. We assessed clinical ROM and impingement testing and found no correlation between proximal femoral characteristics and pre-PAO clinical ROM. Despite this, after correction with PAO, proximal femoral morphology may play a larger intraarticular role. This is reflected by the $84 \%$ of patients in our cohort who 
underwent concurrent head-neck osteochondroplasty based on the intraoperative judgment and assessment of ROM by the senior surgeon (JCC).

Defining proximal femoral anatomy is important in properly understanding the pathology in DDH and therefore guiding proper treatment. Based on our series of selected patients, we conclude that cam-type deformities and decreased head-neck offset in the DDH hip are common. Femoral head asphericity was present in $42 \%$ of hips with maximal head-neck deformity at 2:00 o'clock, and $82 \%$ had reduced head-neck offset at 1:30 o'clock. Because PAO shifts the orientation of the acetabulum, the presence of femoral deformity may lead to impingement if the femoral deformity is unrecognized. We conclude that camtype deformities and decreased head-neck offset in the DDH hip are common and should be closely assessed to prevent secondary FAI during PAO. Future prospective studies should evaluate the influence of proximal femoral anatomy on surgical results of PAO for dysplastic hips.

Acknowledgments We sincerely thank Gail Pashos for her statistical help.

\section{References}

1. Anderson L, Erickson JA, Swann RP, McAlister P, Anderson MB, Sierra R, Peters CL. Femoral morphology in patients undergoing periacetabular osteotomy for classic or borderline acetabular dysplasia: are cam deformities common? J Arthroplasty. 2016;31(Suppl):259-263.

2. Argenson J-NA, Flecher X, Parratte S, Aubaniac J-M. Anatomy of the dysplastic hip and consequences for total hip arthroplasty. Clin Orthop Relat Res. 2007;465:40-45.

3. Beaule P, Zaragoza E, Motamedi K, Copelan N, Dorey F. Threedimensional computed tomography of the hip in the assessment of femoroacetabular impingement. J Orthop Res. 2005;23:12861292.

4. Boese CK, Dargel J, Oppermann J, Eysel P, Scheyerer MJ, Bredow J, Lechler P. The femoral neck-shaft angle on plain radiographs: a systematic review. Skeletal Radiol. 2016;45:19-28.

5. Botser IB, Ozoude GC, Martin DE, Siddiqi AJ, Kuppuswami S, Domb BG. Femoral anteversion in the hip: comparison of measurement by computed tomography, magnetic resonance imaging, and physical examination. Arthroscopy. 2012;28:619-627.

6. Clohisy JC, Carlisle JC, Beaulé PE, Kim Y-J, Trousdale RT, Sierra RJ, Leunig M, Schoenecker PL, Millis MB. A systematic approach to the plain radiographic evaluation of the young adult hip. J Bone Joint Surg Am. 2008;90(Suppl 4):47-66.

7. Clohisy JC, Carlisle JC, Trousdale R, Kim Y-J, Beaulé PE, Morgan P, Steger-May K, Schoenecker PL, Millis M. Radiographic evaluation of the hip has limited reliability. Clin Orthop Relat Res. 2008;467:666-675.

8. Clohisy JC, Dobson MA, Robison JF, Warth LC, Zheng J, Liu SS, Yehyawi TM, Callaghan JJ. Radiographic structural abnormalities associated with premature, natural hip-joint failure. $J$ Bone Joint Surg Am. 2011;93(Suppl 2):3-9.

9. Clohisy JC, Nepple JJ, Ross JR, Pashos G, Schoenecker PL. Does surgical hip dislocation and periacetabular osteotomy improve pain in patients with Perthes-like deformities and acetabular dysplasia? Clin Orthop Relat Res. 2015;473:1370-1377.

10. Clohisy JC, Nunley RM, Carlisle JC, Schoenecker PL. Incidence and characteristics of femoral deformities in the dysplastic hip. Clin Orthop Relat Res. 2008;467:128-134.

11. Clohisy JC, Nunley RM, Curry MC, Schoenecker PL. Periacetabular osteotomy for the treatment of acetabular dysplasia associated with major aspherical femoral head deformities. $J$ Bone Joint Surg Am. 2007;89:1417-1423.

12. Crowe JF, Mani VJ, Ranawat CS. Total hip replacement in congenital dislocation and dysplasia of the hip. J Bone Joint Surg Am. 1979;61:15-23.

13. Eijer H, Myers SR, Ganz R. Anterior femoroacetabular impingement after femoral neck fractures. J Orthop Trauma. 2001;15:475-481.

14. Fabricant PD, Fields KG, Taylor SA, Magennis E, Bedi A, Kelly BT. The effect of femoral and acetabular version on clinical outcomes after arthroscopic femoroacetabular impingement surgery. J Bone Joint Surg Am. 2015;97:537-543.

15. Fujii M, Nakashima Y, Sato T, Akiyama M, Iwamoto Y. Pelvic deformity influences acetabular version and coverage in hip dysplasia. Clin Orthop Relat Res. 2011;469:1735-1742.

16. Fukui K, Trindade CAC, Briggs KK, Philippon MJ. Arthroscopy of the hip for patients with mild to moderate developmental dysplasia of the hip and femoroacetabular impingement: outcomes following hip arthroscopy for treatment of chondrolabral damage. Bone Joint J. 2015;97:1316-1321.

17. Ida T, Nakamura Y, Hagio T, Naito M. Prevalence and characteristics of cam-type femoroacetabular deformity in 100 hips with symptomatic acetabular dysplasia: a case control study. J Orthop Surg Res. 2014;9:93.

18. Ito K, Minka MA, Leunig M, Werlen S, Ganz R. Femoroacetabular impingement and the cam-effect. A MRI-based quantitative anatomical study of the femoral head-neck offset. $J$ Bone Joint Surg Br. 2001;83:171-176.

19. Klaue K, Durnin CW, Ganz R. The acetabular rim syndrome. A clinical presentation of dysplasia of the hip. J Bone Joint Surg Br. 1991;73:423-429.

20. Kohno Y, Nakashima Y, Hatano T, Akiyama M, Fujii M, Hara D, Kanazawa M, Haraguchi A, Iwamoto Y. High prevalence of cam deformity in dysplastic hips: a three-dimensional CT study. $J$ Orthop Res. 2016;34:1613-1619.

21. Konan S, Rayan F, Haddad FS. Is the frog lateral plain radiograph a reliable predictor of the alpha angle in femoroacetabular impingement? J Bone Joint Surg Br. 2010;92:47-50.

22. Larson CM, Moreau-Gaudry A, Kelly BT, Thomas Byrd JW, Tonetti J, Lavallee S, Chabanas L, Barrier G, Bedi A. Are normal hips being labeled as pathologic? A CT-based method for defining normal acetabular coverage. Clin Orthop Relat Res. 2014;473:1247-1254.

23. Lequesne $M$. The normal hip joint space: variations in width, shape, and architecture on 223 pelvic radiographs. Ann Rheum Dis. 2004;63:1145-1151.

24. Li PLS, Ganz R. Morphologic features of congenital acetabular dysplasia. Clin Orthop Relat Res. 2003;416:245-253.

25. Milone MT, Bedi A, Poultsides L, Magennis E, Byrd JWT, Larson CM, Kelly BT. Novel CT-based three-dimensional software improves the characterization of cam morphology. Clin Orthop Relat Res. 2013;471:2484-2491.

26. Murphy SB, Kijewski PK, Millis MB, Harless A. Acetabular dysplasia in the adolescent and young adult. Clin Orthop Relat Res. 1990;261:214-223.

27. Myers SR, Eijer H, Ganz R. Anterior femoroacetabular impingement after periacetabular osteotomy. Clin Orthop Relat Res. 1999;363:93-99. 
28. Nakahara I, Takao M, Sakai T, Miki H, Nishii T, Sugano N. Three-dimensional morphology and bony range of movement in hip joints in patients with hip dysplasia. Bone Joint J. 2014; 96:580-589.

29. Nepple JJ, Martel JM, Kim Y-J, Zaltz I, Clohisy JC. Do plain radiographs correlate With $\mathrm{CT}$ for imaging of cam-type femoroacetabular impingement? Clin Orthop Relat Res. 2012;470:3313-3320.

30. Noble PC, Kamaric E, Sugano N, Matsubara M, Harada Y, Ohzono K, Paravic V. Three-dimensional shape of the dysplastic femur: implications for THR. Clin Orthop Relat Res. 2003;417:27-40.

31. Nötzli HP, Wyss TF, Stoecklin CH, Schmid MR, Treiber K, Hodler J. The contour of the femoral head-neck junction as a predictor for the risk of anterior impingement. J Bone Joint Surg Br. 2002;84:556-560.

32. Nunley RM, Prather H, Hunt D, Schoenecker PL, Clohisy JC. Clinical presentation of symptomatic acetabular dysplasia in skeletally mature patients. J Bone Joint Surg Am. 2011;93(Suppl 2): 17-21.

33. Paliobeis CP, Villar RN. The prevalence of dysplasia in femoroacetabular impingement. Hip. 2011;21:141-145.

34. Peelle MW, Rocca Della GJ, Maloney WJ, Curry MC, Clohisy JC. Acetabular and femoral radiographic abnormalities associated with labral tears. Clin Orthop Relat Res. 2005;441:327-333.

35. Robertson DD, Essinger JR, Imura S, Kuroki Y, Sakamaki T, Shimizu T, Tanaka S. Femoral deformity in adults with developmental hip dysplasia. Clin Orthop Relat Res. 1996;327:196206.
36. Ross JR, Bedi A, Stone RM, Enselman ES, Kelly BT, Larson $\mathrm{CM}$. Characterization of symptomatic hip impingement in butterfly ice hockey goalies. Arthroscopy. 2015;31:635-642.

37. Siebenrock KA, Ferner F, Noble PC, Santore RF, Werlen S, Mamisch TC. The cam-type deformity of the proximal femur arises in childhood in response to vigorous sporting activity. Clin Orthop Relat Res. 2011;469:3229-3240.

38. Sugano N, Noble PC, Kamaric E, Salama JK, Ochi T, Tullos HS. The morphology of the femur in developmental dysplasia of the hip. J Bone Joint Surg Br. 1998;80:711-719.

39. Tönnis D. Congenital Dysplasia, Dislocation of the Hip. New York, NY, USA: Springer; 1987:100-142.

40. Tönnis DD, Heinecke AA. Acetabular and femoral anteversion: relationship with osteoarthritis of the hip. J Bone Joint Surg Am. 1999;81:1747-1770.

41. van Bosse H, Wedge JH, Babyn P. How are dysplastic hips different? A three-dimensional CT study. Clin Orthop Relat Res. 2015;473:1712-1723.

42. Wells J, Millis M, Kim Y-J, Bulat E, Miller P, Matheney T. Survivorship of the Bernese periacetabular osteotomy: what factors are associated with long-term failure? Clin Orthop Relat Res. 2016. Doi:10.1007/s11999-016-4887-z

43. Wenger DE, Kendell KR, Miner MR, Trousdale RT. Acetabular labral tears rarely occur in the absence of bony abnormalities. Clin Orthop Relat Res. 2004;426:145-150.

44. Wiberg G. Studies on dysplastic acetabula and congenital subluxation of the hip joint: with special reference to the complication of osteoarthritis. Acta Chir Scand Suppl. 1939;83:7-135. 